\title{
Observations of the Growth and Decay of Stall Cells during Stall and Surge in an Axial Compressor
}

\author{
Adam R. Hickman and Scott C. Morris \\ University of Notre Dame, Notre Dame, IN 46556, USA \\ Correspondence should be addressed to Adam R. Hickman; adamrhickman@hotmail.com
}

Received 17 March 2017; Revised 1 July 2017; Accepted 27 July 2017; Published 13 September 2017

Academic Editor: Pietro Zunino

Copyright ( 2017 Adam R. Hickman and Scott C. Morris. This is an open access article distributed under the Creative Commons Attribution License, which permits unrestricted use, distribution, and reproduction in any medium, provided the original work is properly cited.

\begin{abstract}
This research investigated unsteady events such as stall inception, stall-cell development, and surge. Stall is characterized by a decrease in overall pressure rise and nonaxisymmetric throughflow. Compressor stall can lead to surge which is characterized by quasi-axisymmetric fluctuations in mass flow and pressure. Unsteady measurements of the flow field around the compressor rotor are examined. During the stall inception process, initial disturbances were found within the rotor passage near the tip region. As the stall cell develops, blade lift and pressure ratio decrease within the stall cell and increase ahead of the stall cell. The stall inception event, stall-cell development, and stall recovery event were found to be nearly identical for stable rotating stall and surge cases. As the stall cell grows, the leading edge of the cell will rotate at a higher rate than the trailing edge in the rotor frame. The opposite occurs during stall recovery. The trailing edge of the stall cell will rotate at the approximate speed as the fully developed stall cell, while the leading edge decreases in rotational speed in the rotor frame.
\end{abstract}

\section{Introduction}

The stable operation of an axial compressor at a given shaft speed is limited at low mass flows by compressor stall. Stall is characterized by a decrease in overall pressure rise and nonaxisymmetric throughflow. A region of low momentum fluid can develop in one or more rotor passages and rotate around the annulus. This region is often referred to as a stall cell. Rotating stall can lead to quasi-axisymmetric fluctuations in mass flow and pressure known as compressor surge. Axial compressors may enter periods of stable rotating stall and surge during operation at off-design conditions. This generally leads to decreased efficiency and increased blade vibration. This paper presents detailed unsteady experimental measurements from a transonic axial compressor in order to describe stall inception, stall cell development, and surging characteristics.

The inception of stall has been the topic of significant research for many years. Camp and Day [1] found that stall inception may occur locally from short length scale disturbances (spikes) or from long length scale disturbances (modes). The present work will focus on observations from a compressor that exhibits spike-type stall inception. Vo [2] found that a criterion for spike-type stall inception is that the interface created from the approach flow and the reverse tip-leakage flow becomes parallel with the rotor leading edge plane. Later Cameron et al. [3] obtained measurements supporting this concept using the compressor used in the present work. Tan et al. [4] provide a comprehensive review on the current understanding of stall inception. They found that the most common type of stall inception for modern compressor designs is a spike-type. This is when the initial stall cell develops on the order of a few rotor revolutions. Stall will typically develop in a single blade passage initially. There have been findings to support the existence of prestall spikes prior to stall inception. Initial disturbances have been found by Weichert and Day [5] found that initial disturbances can occur within the rotor passage at approximately $10-25 \%$ chord from the leading edge. Yamada et al. [6] also found that unsteady flow phenomena appear inside the rotor passage at near-stall.

After stall inception, a stall cell will increase in circumferential and radial extent. The stall cell will span multiple rotor 
passages as it rotates around the annulus. Cameron et al. [7] found that the leading edge of the stall cell will initially rotate at a slower rate in the laboratory frame. The trailing edge of the stall cell will initially rotate around the annulus at nearly the rotor speed. After a few revolutions the leading edge will increase in rotational speed and the trailing edge will decrease in rotational speed as the final size is reached. Day [8] gives a thorough review of the current understanding of rotating stall. Day found throughout many compressors described in the literature that smaller stall cells tend to travel faster in the laboratory frame than larger cells.

The system dynamics of stall and surge for a compression system has been studied extensively. Greitzer [9, 10] developed a lumped parameter model to predict the fluctuations in mass flow and plenum pressure during stall and surge. The Greitzer stall and surge model can be used to predict the point where, as a compressor reaches the stall limit, stall will transition to surge. In his work, Greitzer found that a single nondimensional parameter, termed the $B$ parameter, was a good indicator to determine whether stall or surge would occur. Hickman and Morris [11] found that the poststall throttle point can also influence the onset of surge.

Surge can grow from rotating stall as the compressor interacts with compression system. Day [12] found that the flow breakdown around the rotor caused by a stall inception event is typically the reason for the onset of surge. Compressor surge is composed of multiple parts [13]. The developing stall cell produces an effective blockage of the compressor annulus. A sudden drop in pressure ratio and mass flow rate then follow [11]. Rotating stall may be present from stall inception until the surge recovery process, [14] depending on the compressor. The recovery process occurs where the compressor will recover from rotating stall briefly. During the brief stall recovery process, the pressure ratio returns to its prestall value. Another stall inception event and surge cycle repeat as the stall point is reached again [11].

Observations from measurements of stall inception, rotating stall, surge, and stall recovery are presented. This paper includes a description of the test facility and instrumentation used. Instantaneous shroud and rotor exit unsteady pressure contours are presented during transient events in order to better understand the process of stall inception and stall development. A comparison between stall and surge events is also given to describe how the onset of surge occurs [15].

\section{Experimental Methods}

2.1. Compressor Test Facility. Experiments were conducted using the Notre Dame Transonic Axial Compressor Facility (NDTAC). The NDTAC facility includes a butterfly valve and plenum upstream of the axial compressor and a second plenum and butterfly valve downstream. The upstream and downstream plenum volumes were approximately $1.52 \mathrm{~m}^{3}$ and $0.70 \mathrm{~m}^{3}$, respectively. The NDTAC facility employed a magnetic bearing system where the rotor shaft was levitated by a series of magnets. This enabled the facility to safely operate in rotating stall for extended periods of time and surge for short periods.
TABLE 1: ND Stage 04 design parameters.

\begin{tabular}{lc}
\hline Quantity & Value \\
\hline Tip dia. $[\mathrm{m}]$ & 0.457 \\
Inlet hub dia. $[\mathrm{m}]$ & 0.343 \\
Exit hub dia. $[\mathrm{m}]$ & 0.368 \\
Rotor axial chord [cm] & 3.56 \\
Rotor blade count & 20 \\
Stator count & 43 \\
$N_{c}[\mathrm{rpm}]$ & 14684 \\
$U_{\text {tip }}[\mathrm{m} / \mathrm{s}]$ & 352 \\
\hline
\end{tabular}

The compressor used in the experiments was ND Stage 04, a single stage transonic axial compressor with a mean hub-to-tip ratio of approximately 0.78 . Figure 1 shows the schematic of the cross-section of ND Stage 04. Table 1 shows the design parameters for this stage. This compressor stage includes an annular contraction that incorporates a perforated plate which provided an approximate 3.5\% turbulence intensity to the stage. The test article included a rotor and stator configuration.

2.2. Instrumentation. Steady and unsteady instrumentation were utilized for this work. Figure 1 shows the measurement planes. Standard Kiel probes to measure steady-state total temperature and total pressure were located at 3.2 axial rotor chords $\left(c_{\mathrm{ax}}\right)$ upstream of the rotor leading edge and $0.77 c_{\mathrm{ax}}$ downstream of the rotor trailing edge. Unsteady instrumentation was located upstream, downstream, and over the rotor.

Constant temperature hot wires were used to measure the unsteady stage inlet velocity and track the development of the stall cell during transient events. A circumferential array of 4 hot wires spaced every $90^{\circ}$ were positioned approximately $8.9 c_{\mathrm{ax}}$ upstream of the rotor leading edge at midspan of the flow path. The hot wires were $5 \mu \mathrm{m}$ tungsten wire probes and oriented normal to the flow and in the radial direction. Using the form of King's law presented by Bruun [16], a simple calibration was found to relate the voltage and flow velocity. The velocities from the four hot wires were averaged in order to estimate the time-resolved and the annulus average unsteady mass flow. The hot-wire frequency response was in excess of $100 \mathrm{kHz}$.

High-response pressure transducers were utilized for flow field measurements in the plenums and in the vicinity of the rotor. Figure 2 is a schematic of the locations of unsteady instrumentation around the rotor. The pressure sensors used in the experiments were silicon piezoresistive pressure sensors made by Kulite (model XTL-140-25A). These pressure transducers had a natural frequency of approximately $240 \mathrm{kHz}$. Kulite pressure transducers were located in the upstream and downstream plenums. A circumferential array of ten high-frequency pressure transducers, located approximately $0.18 c_{\mathrm{ax}}$ upstream of the rotor leading edge, were flush mounted to the flow surface of the shroud. This allowed tracking of the stall-cell development and calculation of the circumferential size of the stall cell. A line of thirteen 


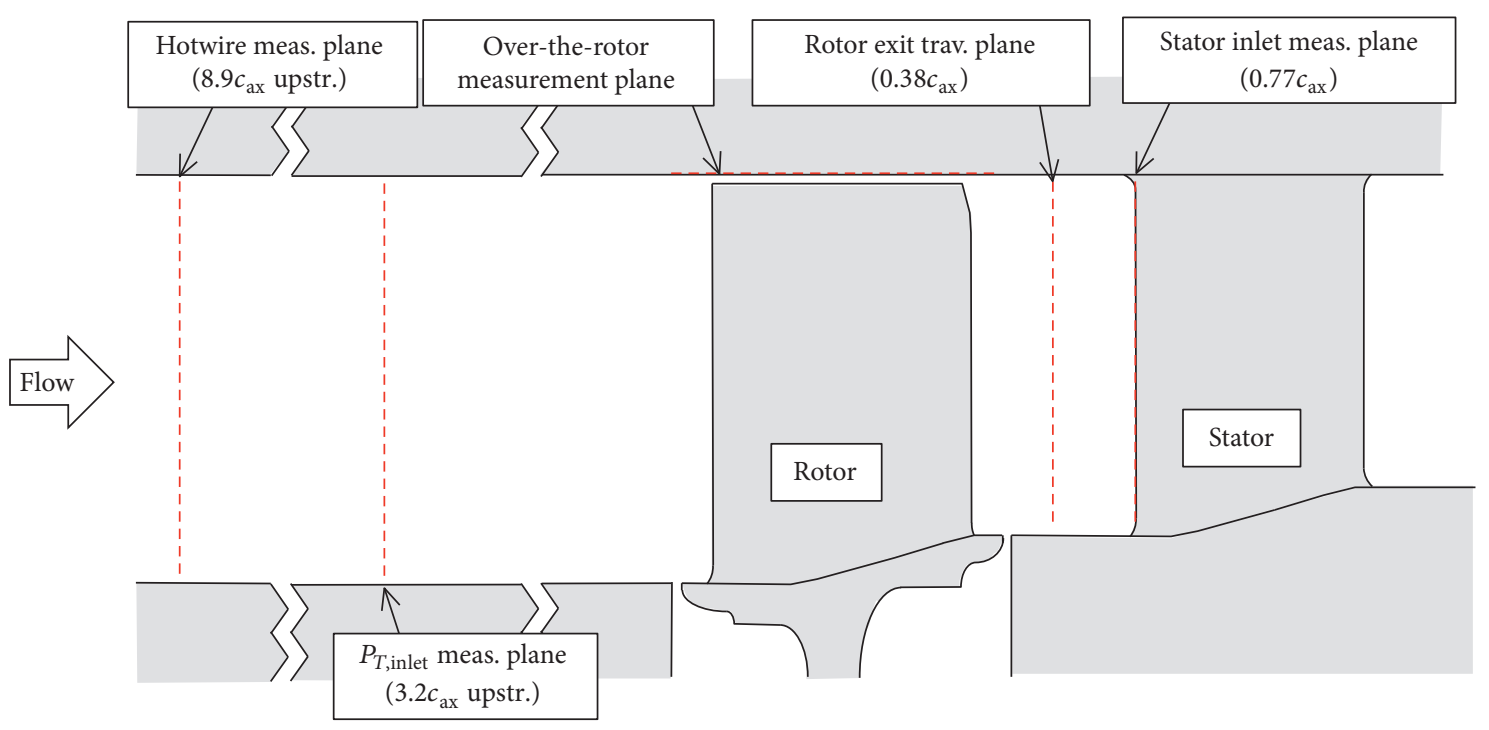

FIGURE 1: Cross-section of ND Stage 04.

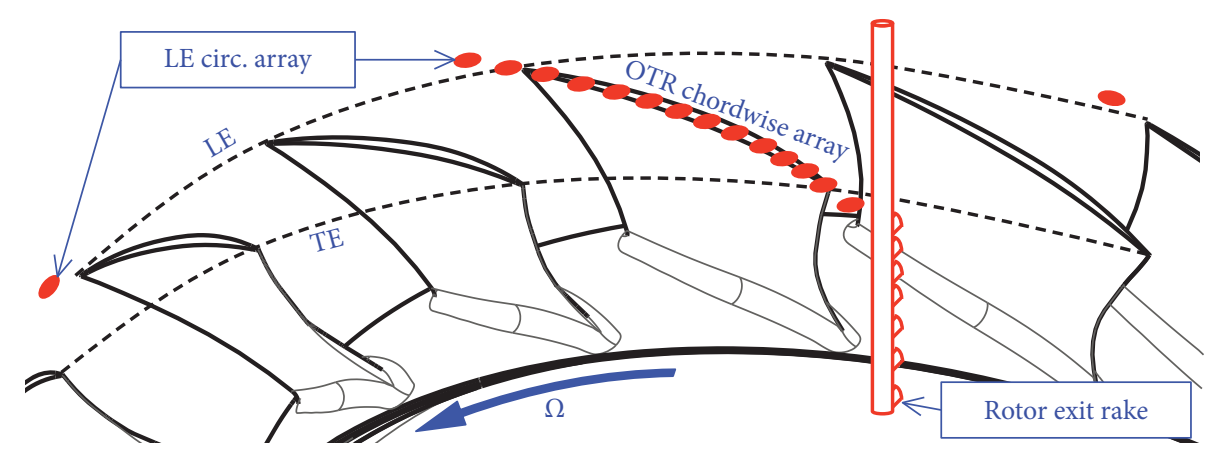

FIGURE 2: Schematic of near rotor unsteady instrumentation.

high-frequency pressure sensors was also located directly over-the-rotor (OTR) in a chord-wise array. The array of OTR transducers was flush mounted to the flow surface following the stagger angle of the rotor blade tip similar to Weichert and Day [5].

An unsteady total pressure rake was specifically designed for this work. The top of Figure 3(a) shows a photograph, and the bottom shows a schematic of the total pressure rake. The rake contained seven miniature Kulite transducers (XCQ95-062) which were mounted into separate Kiel heads such that the transducer was directly exposed to the oncoming flow. Some have designed unsteady total pressure probes such that the transducer is in the body of probe [17]. Though this design can protect the sensor from dust and debris, it can limit the frequency response of the probe. The multiple sensors were positioned along the length of the probe and were concentrated towards the tip region of the rotor. It was installed at the rotor exit traverse plane shown in Figures 1 and 2 . The unsteady total pressure rake was used to record unsteady total pressures simultaneously at multiple spanwise locations during stall and surge.
Because this was an unconventional design, a yaw sensitivity test was conducted for the developed unsteady total pressure rake. Figure 3(b) shows the total pressure normalized by the maximum as a function yaw angle for one of the transducers. All transducers contained nearly identical yaw sensitivity. The unsteady total pressure rake was found to have an acceptance angle limit of approximately $\pm 20^{\circ}$. Beyond the acceptance range, the measured pressure is biased low and drops gradually compared to a standard Kiel probe at approximately $0.4 \%$ per degree.

Unsteady instrumentation was sampled at rate of $200 \mathrm{kHz}$. It was found that the sampling rate and frequency response of the sensors were sufficient to measure the frequencies associated with stall inception and rotating stall events at the speeds considered. The maximum frequencies of interest were found to be under $20 \mathrm{kHz}$. The Kulite sensors were calibrated before the measurement program and were found to have an uncertainty less than $1 \%$ of the full-scaled values. Hot-wire measurements were also calibrated immediately prior to the measurements and were found to have an uncertainty of approximately $3 \%$ of the measured values. 

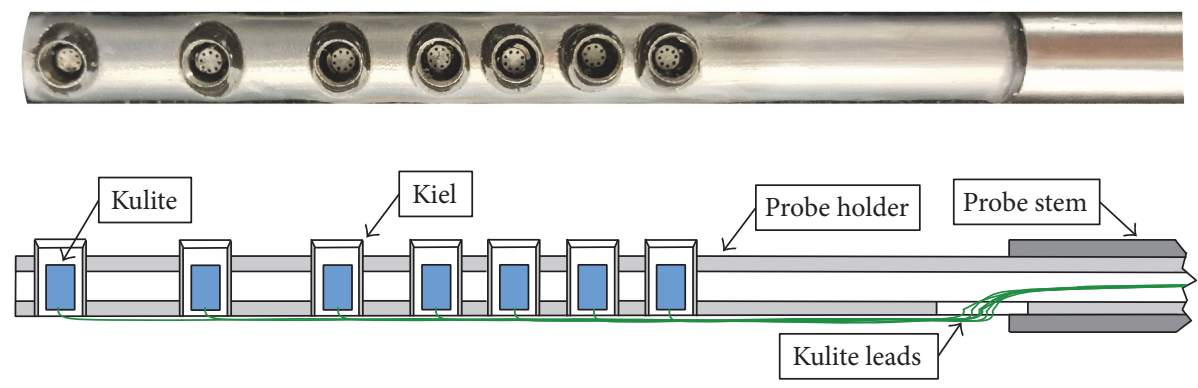

(a)

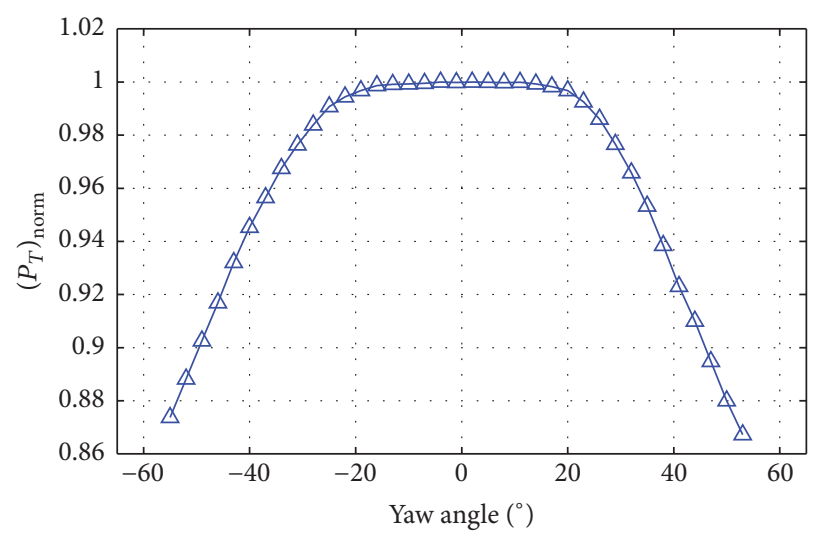

(b)

Figure 3: (a) Photograph and schematic of the unsteady total pressure rake and (b) the yaw response.

\section{Steady and Unsteady Compressor Characteristics}

This section presents the steady-state compressor characteristic and unsteady characteristics during two poststall events at $100 \%$ design speed. First, the steady-state normalized plenum pressure rise $(\Delta P)$ is shown as a function of flow coefficient $\left(C_{x} / U\right)$ for ND Stage 04 at $100 \%$ design speed in Figure 4 . The unstalled branch of the steady characteristic contains a steep negative slope. The stall point was found at approximately $C_{x} / U=0.34$. Upon throttling the compressor beyond stall, the mass flow and pressure rise decrease abruptly. A black dashed line connects the last stable prestall point to the initial stall point. The rotating stall branch of the steady-state compressor characteristic below the value of $C_{x} / U=0.29$ was approximated using data at lower speeds as discussed in Hickman and Morris [11]. This portion of the characteristic was used strictly for predictions of unsteady compressor characteristics and contains a nearly constant pressure rise as the mass flow decreases. The steady characteristic includes a stall/unstall hysteresis portion. Upon opening the valves, the characteristic deviates from the original path. The pressure rise remains relatively constant as the mass flow increases to approximately $C_{x} / U=0.32$. This was found to be the critical recovery value for this compressor at $100 \%$ design speed. Upon opening the throttle valves beyond this point, the compressor recovered from rotating stall.
The measured unsteady compressor characteristics for a stall and surge case at $100 \%$ design speed are also shown in Figure 4. The markers along the measured curves indicate every 5 rotor revolutions. The unsteady events were recorded back-to-back with identical speeds and identical values of the upstream and downstream $B$ Parameter $\left(B_{U}=2.52, B_{D}=\right.$ 1.71). The single difference between the stall and surge case is the poststall throttle point. The ending throttle point for the stall case (blue) corresponded to the initial stall point. The compressor was "eased" into stall by closing the valves up to and not past the initial stall point. After the compressor stalled, the mass flow and pressure rise decreased past the initial stall point. The mass flow and pressure rise then increased, or rebounded, such that it did not surpass the critical recovery value of $C_{x} / U$. The compressor then entered stable stall.

For the surge case (red) in Figure 4, the poststall throttle point is denoted by the red dashed line. The compressor was throttled deeper into stall past the initial stall point. The decrease in pressure rise and mass flow are more dramatic. The rebounding motion of the compressor characteristic is such that it surpasses the critical recovery value of $C_{x} / U$ and the compressor temporarily recovers from stall. The compressor then returns back to the initial stall point. Not shown in Figure 4 is that after the compressor is again brought to the stall point, another surge cycle begins similar to the first. A further analysis of the development of the stall cell and comparison between the stall and surge case will be discussed 


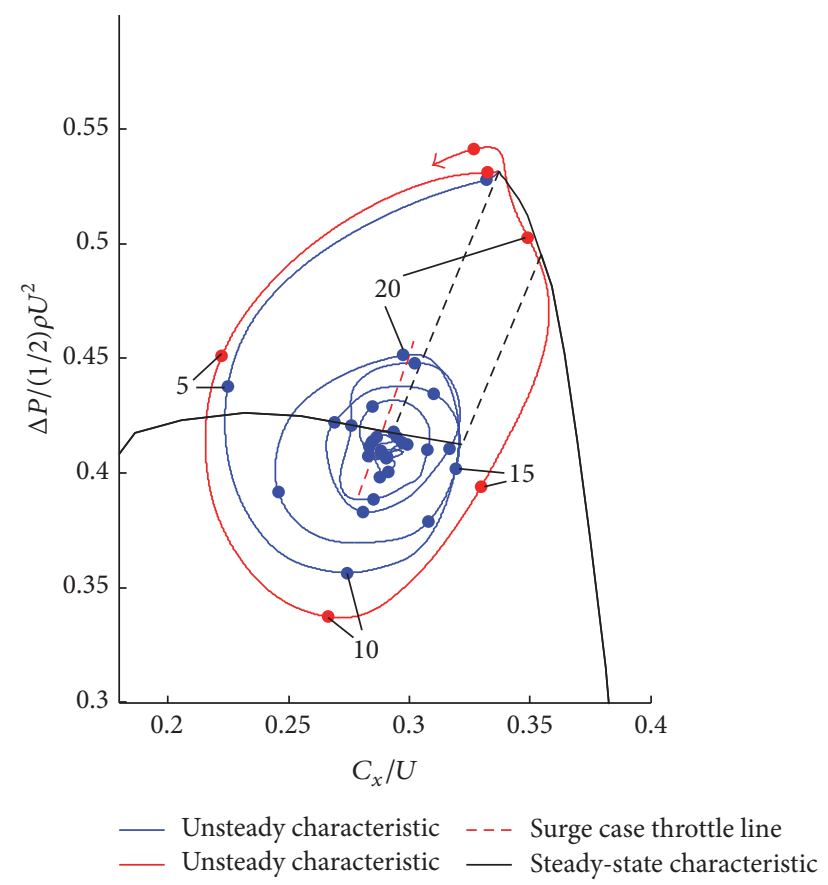

FIGURE 4: Steady and unsteady $100 \%$ corrected speed compressor characteristics.

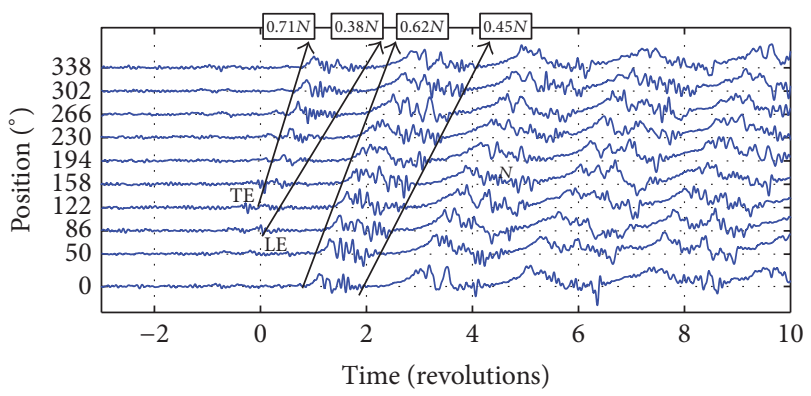

Figure 5: Time series from the circumferential array of static pressures upstream of the rotor leading edge.

in the following sections. All of the following data and results presented were acquired at the $100 \%$ design speed.

\section{Stall Inception and Stall-Cell Development Measurements}

4.1. Leading Edge Shroud Static Pressure Time Series. Stall inception events were recorded using the unsteady instrumentation described in Section 2.2. Figure 5 shows the pressure traces from the circumferential array of high-frequency pressure transducers during a typical stall inception event at $100 \%$ corrected speed. The abscissa is plotted in units of rotor revolutions and extends from -3 to 10 revolutions. The ordinate represents both the circumferential position and magnitude of the fluctuations at the position. Time series are low-pass filtered at 15 times the shaft rate $(15 N)$, just below the blade passing frequency such that the development of the rotating stall cell can be tracked. It was found that

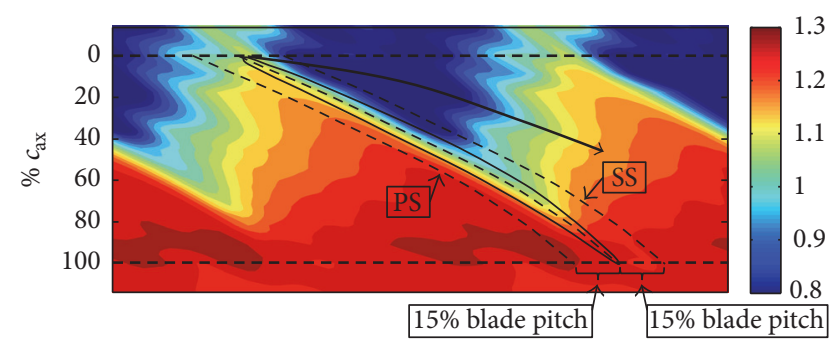

FIgURE 6: Ensemble average shroud static pressure at prestall conditions.

stall inception occurred in the same circumferential location repeatedly. This was most likely due to some slight asymmetry in the inlet flow path.

The origin of the time axis corresponds to the time when the fluctuations become greater than prestall fluctuations. At approximately revolution 0 , a single stall cell or spike begins to form and rotate around the annulus. A static pressure rise occurs upstream of the blade row similar to Pullan et al. [18], which extends over the span of multiple blade passages. Initially, the trailing edge of the stall cell rotates at a rate of $0.71 \mathrm{~N}$ and slows down in the laboratory frame as the stall cell increased in circumferential size. The leading edge rotates at $0.38 \mathrm{~N}$ in the laboratory frame initially and increases rotational speed as the cell develops. These observations are consistent with short length scale, or "spike" type stall inception.

In the frame of the rotor the leading edge of the stall cell initially rotates at approximately $0.62 \mathrm{~N}$ while the trailing edge rotates at only $0.29 \mathrm{~N}$. Thus, the stall cell grows on the leading edge side of the cell initially. Rotor passages at the leading edge of the stall cell stall at a faster rate relative to passages exiting the cell during the initial growth phase.

4.2. Prestall Shroud Static Pressure. To compare to stall inception measurements, the prestall phase-locked average shroud static pressure normalized by the inlet plenum pressure, $P_{\mathrm{PU}}$, is presented in Figure 6. This contour corresponds to the shroud static pressure at the last stable operating point prior to stall inception. Evidence of the tip clearance vortex as discussed in Weichert and Day [5] can be seen by a low pressure core that extends from the suction side (SS) of the rotor leading edge towards the middle of the pressure side (PS) of the adjacent blade. The path is denoted by the black arrow in Figure 6.

4.3. Stall Inception. Prior to the earliest detectable signs by the circumferential array of high-frequency pressure transducers, evidence of stall inception can be seen within rotor passages. Figure 7 shows the shroud static (top) and rotor exit total (bottom) raw pressure time series. These data are measured using the OTR chord-wise array and unsteady total pressure rake described in Section 2.2. The centers of the contours in Figure 7 are at approximately revolution -0.8 at the $0^{\circ}$ circumferential position. The raw data are displayed as a contour normalized by $P_{\mathrm{PU}}$, where the ordinates are in space and the abscissa is in time. This gives an "instantaneous view" of the shroud static pressure and rotor exit total pressure, 

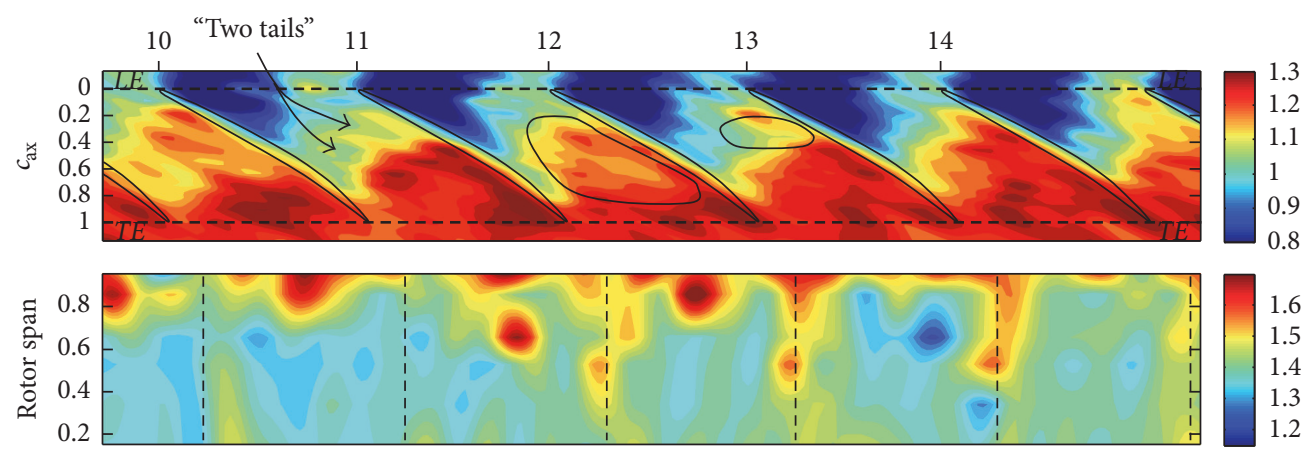

FIGURE 7: Instantaneous (space-time) shroud static and rotor exit pressure contour centered at revolution -0.8 of Figure 5 at the $0^{\circ}$ circumferential position.

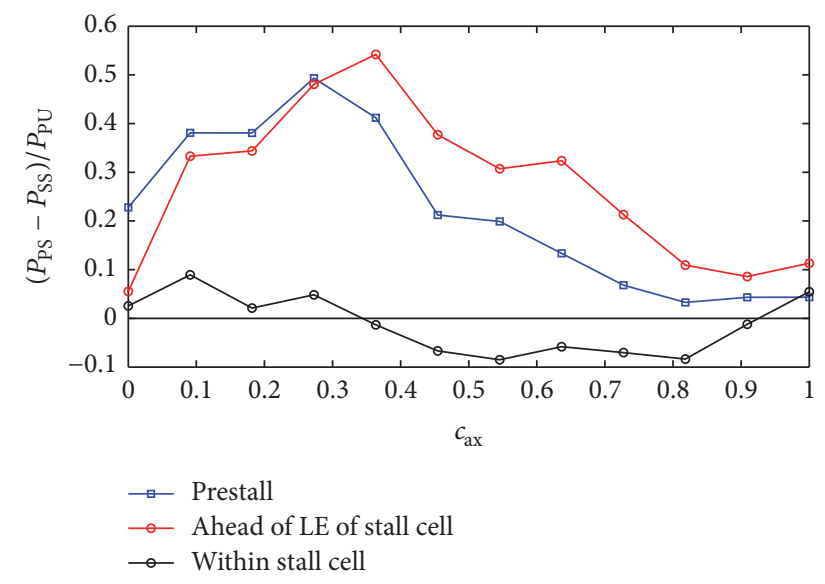

FIGURE 8: Rotor blade tip loading at prestall and poststall conditions.

assuming the flow field evolves slowly with respect to the blade passage time scale. Blade locations are overlaid for reference in the shroud contours. Approximate locations of the rotor wake are denoted with vertical dashed lines in the rotor exit contours. All instantaneous contours in this section are captured during the unsteady event shown in Figure 5, but the characteristics described in this section were found to be similar throughout the majority of stall inception events for this compressor.

Many repeatable features were found similar to Weichert and Day [5] such as the existence of the "two-tail" phenomenon. This feature can be seen in the shroud static pressure contour between blades 10 and 11 of Figure 7. This is an indication that the tip clearance vortex is disturbed. The two passages to the right show regions of low pressure. These regions are circled and indicate signs of prestall spikes. The blade loading for blades 12 and 13 decreases as a result of the low pressure regions. The rotor passage between blades 13 and 14 returns close to prestall values as compared to Figure 6.

The rotor exit pressure contours in Figure 7 show a large degree of unsteadiness from one passage to another. For this compressor, the vertical streaks of higher total pressure are typically associated with the blade wakes as these measurements are in the absolute frame. This contour shows no obvious signs of disturbed flow, and it will be shown that the values closely resemble prestall values for this moment in time.

4.4. Blade Lift and Spanwise Rotor Exit Total Pressure. To better quantify instantaneous values, the blade loading was approximated and compared to prestall values. As there was no unsteady instrumentation on the rotor to calculate loading on the blade, the blade loading was approximated from the shroud static pressure measurements from the OTR chordwise array. The dashed line to the left of the blade in Figure 6 was defined as the sample location for the pressure on the PS of the rotor blade. The sample location was approximately $15 \%$ of a blade pitch from the mean camber line of the blade. A similar method was used to define the pressure on the SS of the rotor blade. The difference between the PS and SS at each axial location was assumed to be the blade loading at the tip of the rotor.

This method was used to determine the blade loading during stable prestall operation and poststall events. Figure 8 shows the average blade loading for prestall conditions and two poststall conditions. Curves in this figure are plotted as blade loading normalized by $P_{\mathrm{PU}}$ as a function of axial location. The blue curve in Figure 8 is the average prestall blade loading prior to stall inception. During prestall conditions, the rotor blade is more highly loaded towards the leading edge of the blade and exhibits the highest loading at approximately $0.27 c_{\mathrm{ax}}$.

The blade lift at the rotor tip was approximated during the steady prestall operation and poststall events. The blade lift was found by integrating the blade loading curve along the axial direction. For poststall events, blade lift was calculated as individual blades passed by the over-the-rotor chord-wise array. Figure 9(a) shows the blade lift at the $0^{\circ}$ circumferential position during the stall inception event shown in Figure 5. Values are normalized by the mean of the prestall lift. The prestall lift can fluctuate from unsteadiness in the flow through the rotor. Statistics were performed on the lift in the prestall region immediately prior to stall inception. The grey band in Figure 9(a) represents values bounded by plus and minus one standard deviation from the mean of the prestall region. The spanwise average total pressure was also calculated and is shown in Figure 9(b). Values are normalized by the mean of the prestall rotor exit total pressure. The 


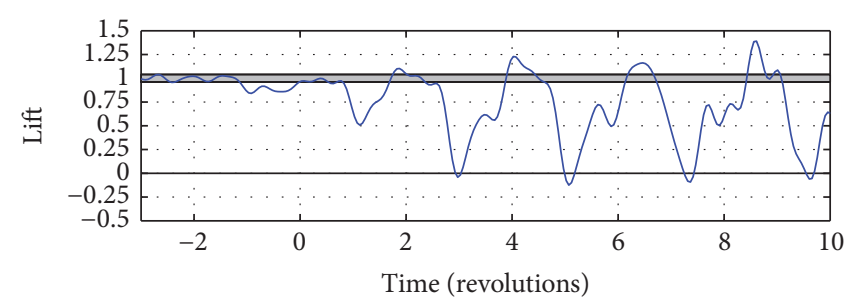

(a)

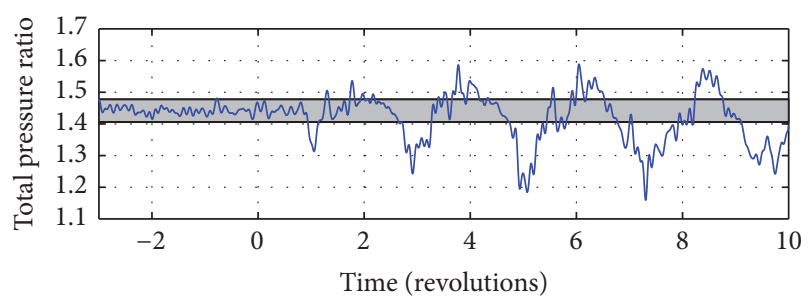

(b)

FIGURE 9: (a) Blade lift at rotor tip and (b) spanwise average rotor exit total pressure ratio at the $0^{\circ}$ circumferential location.

spanwise average total pressure was found by averaging multiple pressures along the span measured by the unsteady total pressure rake at the $0^{\circ}$ circumferential position. The grey band in Figure 9(b) also represents values bounded by plus and minus one standard deviation from the mean of the prestall region.

At approximately -0.8 revolutions, corresponding to the instantaneous contours in Figure 7, there is a statistically significant decrease in lift at the tip. At the same moment in time, the spanwise average total pressure ratio shows no deviation from the prestall. The first moment that the compressor experiences a significant decrease in total pressure is at approximately revolution 1.1, which corresponds to the first stall cell passing. By this time, the stall cell has grown in circumferential size and is clearly noticeable in Figure 5 . This result agrees well with the work of Weichert and Day [5] that the first sign of stall inception spikes occurs within a rotor passage.

4.5. Stall-Cell Development. As the stall cell develops, blade lift and rotor total pressure fluctuate dramatically. The first instance the stall cell passes the OTR chord-wise array and unsteady total pressure rake is between revolutions 0.8 and 1.7. The trailing edge of the stall cell is at approximately 0.8 revolutions and the leading edge is at approximately 1.7 revolutions. Moving forward in time, as the trailing edge of the stall cell propagates to the $0^{\circ}$ circumferential location at 0.8 revolutions the lift and total pressure ratio begin to decrease. By revolution 1, within the stall cell, the lift decreases to approximately $50 \%$ of the prestall value. The pressure ratio decreases to nearly 1.3. The stall cell has not yet fully developed, and the decrease in lift and pressure ratio are not as drastic as future stall cell passing. At revolution 1.7, ahead of the leading edge of the stall cell, the lift and pressure ratio are both slightly above prestall values. This suggests increased incidence and turning ahead of the stall cell.

It is useful to analyze the raw unsteady pressure time series to better visualize the growth of the stall cell. Figure 10 shows the instantaneous shroud static pressure and rotor exit total pressure contours during the first stall cell passing. Contours in Figure 10(a) are centered at revolution 0.9 and show the trailing edge of the stall cell. In this figure, passages to the left of blade 7 are exiting the stall cell and are in the process of recovering. The passages increase in blade loading and pressure ratio to the left of blade 7. Passages to the right of blade 7 are stalled with little blade loading and pressure ratio.

Figure 10(b) shows the leading edge of the stall cell. This contour is centered at revolution 1.1. Blade 12 exhibits a relatively high pressure difference across the blade in the shroud static pressure contour. The rotor exit contour shows pressures near prestall values. To the left of blade 12 , the blade loading and rotor exit total pressure progressively decrease. Passages between blades 10 and 12 are entering the leading edge of the stall cell and are in the process of stalling. Passages to the left of blade 10 are stalled and show little pressure rise across the rotor.

Passages ahead of leading edge of the stall cell are shown in Figure 10(c), centered at revolution 1.7. These blades show an increase in blade loading and pressure ratio above the prestall values as discussed previously. These passages are overpressured and are approaching the stall cell.

After rotor revolution 2, the stall cell has become fully developed. Figure 9 shows the blade lift and pressure ratio for three more stall cell revolutions. Within the fully developed stall cell, the blade lift decreases to slightly below zero at revolutions 3, 5.1, and 7.3. The blade loading at approximately revolution 3 is shown in Figure 8 as the black curve. The blade loading between $0.35 c_{\mathrm{ax}}$ and $0.9 c_{\mathrm{ax}}$ is less than zero for this moment in time. This is evidence of localized back-flow through the rotor passage as the stall cell passes. The rotor total pressure ratio decreased as low as 1.2 within the stall cell (Figure 9(b)).

The blade lift increased significantly ahead of the stall cell at revolutions 4, 6.4, and 8.6. At revolution 8.6, blade lift increased approximately $40 \%$ above prestall values. The blade loading at approximately revolution 4.1 is shown in Figure 8 as the red curve. The loading from the rotor leading edge to $0.25 c_{\mathrm{ax}}$ is slightly below the average prestall loading. From $0.25 c_{\mathrm{ax}}$ to the trailing edge of the rotor, the blade shows increased loading compared to the prestall. The rotor exit total pressure also increased significantly ahead of the developed stall cell as high as approximately 1.59 as shown in Figure 9(b).

\section{Stall and Surge Time Series}

The development of the stall cell was remarkably similar between cases when the compressor entered stable rotating stall and when the compressor surged. This section will provide a detailed comparison between the two unsteady events shown on the left of Figure 4.

Both the stall and surge cases exhibited a sharp decrease in $C_{x} / U$ and $\Delta P$ during the stall inception event. Figures $11(\mathrm{c})$ and 11(d) show a comparison of $C_{x} / U$ and $\Delta P$ between the stall and surge cases. In these figures, the blue curve is 


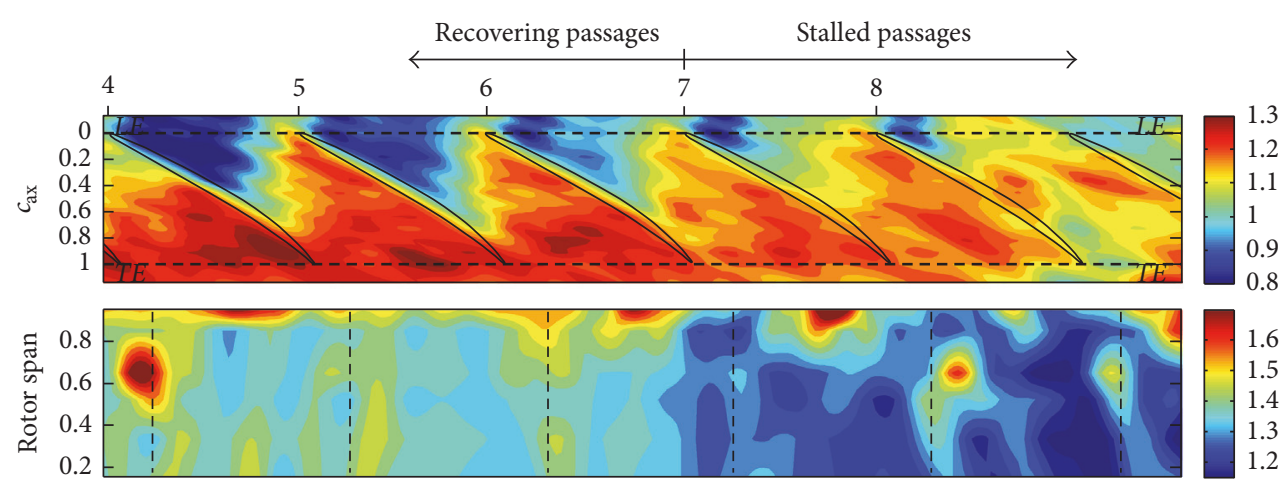

(a)

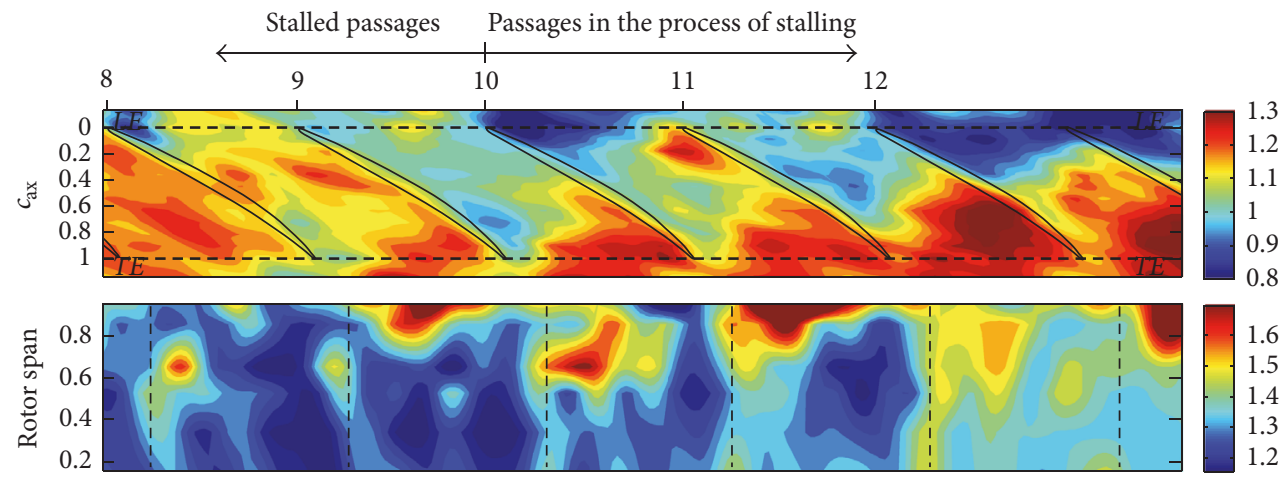

(b)

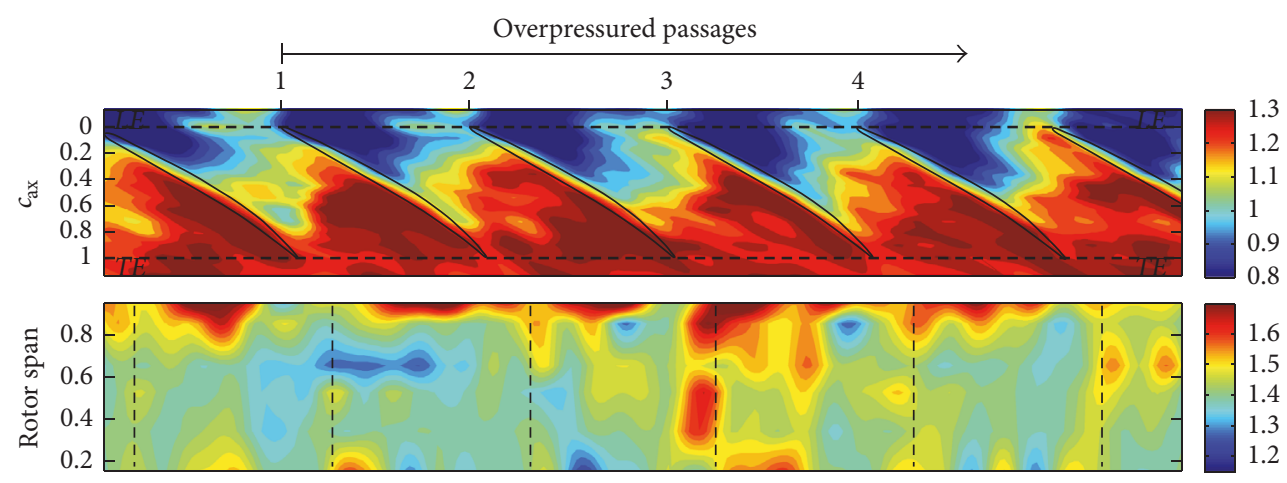

(c)

FIGURE 10: Instantaneous (space-time) shroud static and rotor exit pressure contours centered at revolution (a) 0.9 , (b) 1.1, and (c) 1.8 of Figure 5 at the $0^{\circ}$ circumferential position.

the $100 \%$ corrected speed stall case and the red curve is the $100 \%$ corrected speed surge case. The surge case shows a larger decrease in plenum pressure rise and mass flow compared to the stall case. The larger decrease produces a large enough return swing during the recovery to surpass the critical recovery value of $C_{x} / U$ [11]. The critical recovery value of $C_{x} / U$ is shown as the black line in Figure 11(c). The fluctuations in the stall case are just small enough such that the trajectory of the unsteady characteristic never surpasses the critical recovery value of $C_{x} / U$. This can be seen more clearly in Figure 4 . The trajectory of the blue experimental curve approaches the critical recovery value of $C_{x} / U$ on three occasions, but does not go above. It is the existence of a relatively large stall/unstall hysteresis branch in the steady-state characteristic that allows this to occur.

Figures 11(a) and 11(b) show the low-pass filtered time traces of shroud static pressure and upstream hot wires for both the stall and surge cases. These figures illustrate the similarities between the two stall inception events. From rotor revolutions 0 to 14 the traces are similar. Stall inception occurs at approximately the same circumferential location. The initial growth and rotation rates of the stall cell during the first few revolutions between the two cases are nearly identical. At approximately revolution 5, the speed of the stall cell was $0.44 \mathrm{~N}$ in the laboratory reference frame. At this point, the stall cell was at its largest size and rotating the 

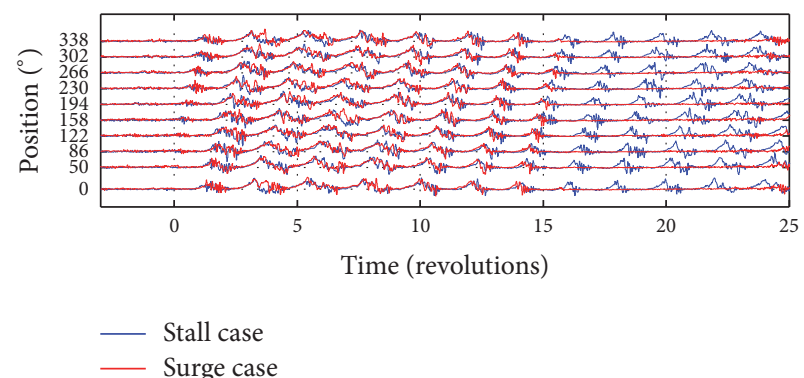

(a)

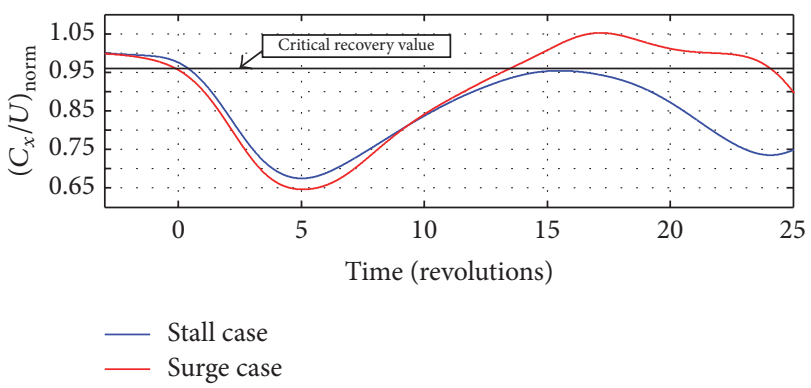

(c)

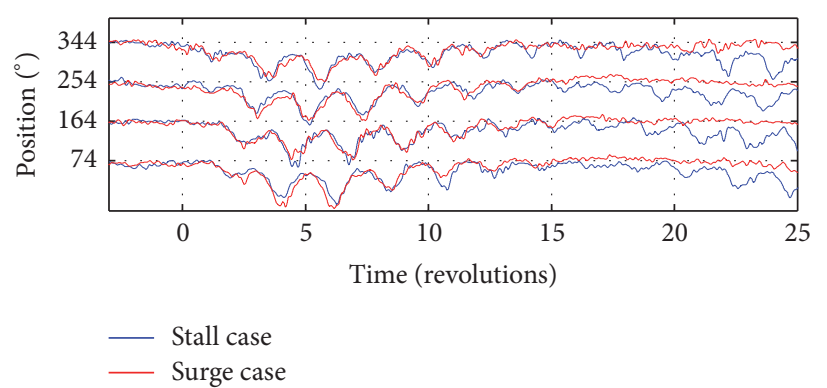

(b)

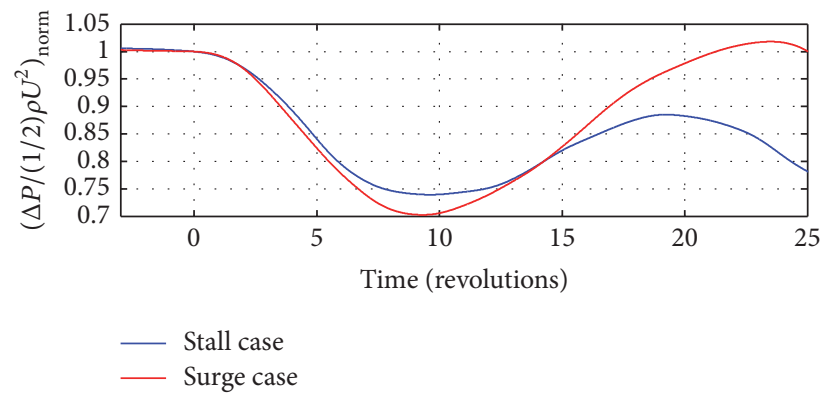

(d)

FIGURE 11: Time series of (a) circumferential array of static pressures upstream of the rotor leading edge, (b) circumferential array of hot wires upstream of the rotor leading edge, (c) annulus average mass flow, and (d) plenum-to-plenum pressure rise during stall (blue) and surge (red).

slowest. This coincides with the local minimum on the $C_{x} / U$ trace in Figure 11(c). As the mass flow recovers, the stall cell then begins to decrease in circumferential size and increase in speed until approximately revolution 15 where $C_{x} / U$ was at its local maximum for the stall case. The speed of the stall cell for the stall case at revolution 15 was approximately $0.52 \mathrm{~N}$.

The shroud static pressure traces in Figure 11(a) for the surge case show a second peak for approximately half of a revolution of the stall cell between rotor revolutions 3 and 4 . This second peak is most apparent in Figure 11(a) at the $0^{\circ}$ circumferential position and at rotor revolution 4 . This extra disturbance may have been due to the mass flow being slightly lower for the surge case. A decrease in mass flow may have increased the incidence angle possibly allowing for a second spike to briefly form at the leading edge of the main stall cell.

In the surge case, the critical recovery value of $C_{x} / U$ was surpassed at approximately rotor revolution 13.5. It was at this point that the stall recovery process began for the compressor in the surge case. This is when the shroud static pressure traces and upstream hot-wire traces for the surge case begin to deviate from the stall case. With the compressor recovered from rotating stall, the plenum pressure rise recovered until the compressor was brought to the stall point again in the surge case. At revolution 24 of the surge case, a second stall inception event occurred and another surge cycle began. Figures 11(a) and 11(b) show how similar the stall inception events are for the stall and surge case. These results show it is purely the poststall throttling point in conjunction with the system dynamics that determine whether surge will grow from rotating stall. For a further analysis of the rotating stall case see Hickman and Morris [19].

\section{Temporary Surge and Stall Recovery}

During the temporary stall recovery at the end of the surge cycle, the leading edge and trailing edge of the stall cell will travel at different speeds. Figure 12(a) shows the shroud static pressure traces from the circumferential array for the surge case from rotor revolutions 10 through 18 . The speeds of the leading edge and trailing edge of the stall cell are labeled. As the compressor begins to recover, the trailing edge of the stall cell rotates at approximately the same speed as when the cell was fully developed. The leading edge of the stall cell rotates at a faster rate in the laboratory frame as the cell is shrinking. In the rotor frame, the leading edge of the stall cell rotates more slowly until the leading edge and trailing edge meet and the stall cell disappears. This is very similar to a compressor recovering from stable rotating stall.

Data were acquired during the recovery from stable rotating stall. Figure 13 shows the unsteady characteristic for a rotating stall and stall recovery event. The markers along the solid blue curve represent every 2 rotor revolutions. The zero location was chosen as the approximate point where stall cell dies out. The unsteady characteristic during the stall event is shown as the blue dashed line for reference in Figure 13. In this case the compressor entered stable rotating stall by closing the valves. The valves were then opened and the compressor recovered from rotating stall. The solid blue line is the unsteady characteristic during the stall recovery event. The characteristic starts at the initial stall point and at approximately rotor revolution -2 , the unsteady characteristic surpasses the critical recovery value of $C_{x} / U$, and the stall recovery process begins. The unsteady characteristic 


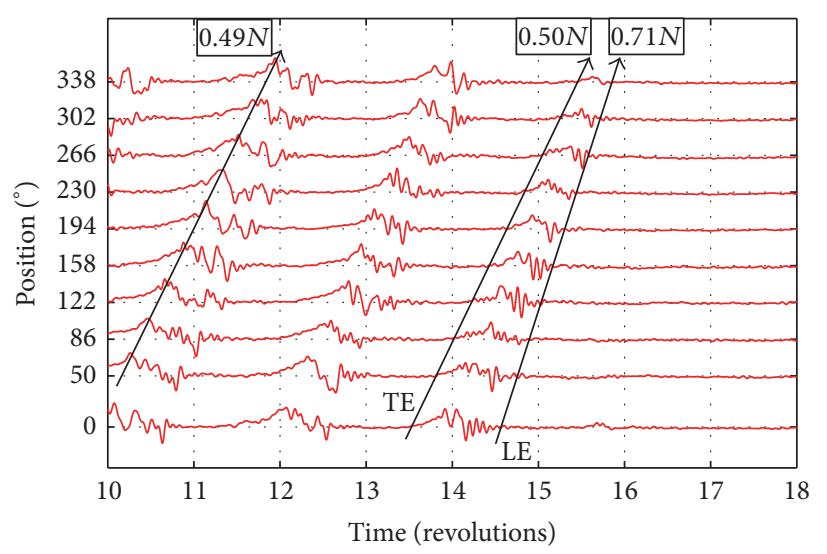

(a)

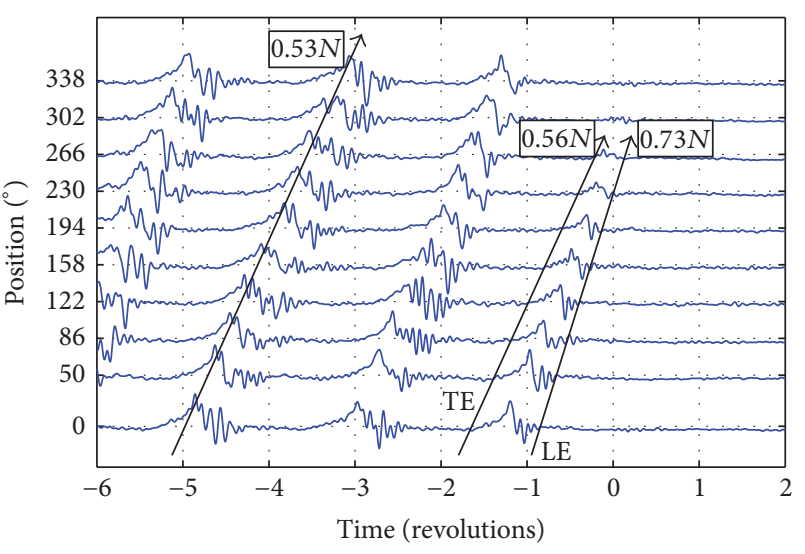

(b)

FIGURE 12: Time series of circumferential array of static pressures upstream of the rotor leading edge during (a) temporary recovery at the end of a surge cycle and (b) stall recovery with an opened outlet valve.

transiently attaches to the unstalled branch of the steady-state compressor characteristic.

In Figure 12(b) are the leading edge traces for the stall recovery event shown in Figure 13. The time axis corresponds to the labeled markers in Figure 13. The speeds of the trailing edge and leading edge of the stall cell during stall recovery are similar to the temporary stall recovery at the end of a surge cycle. The trailing edge rotates at approximately the same speed as the developed stall cell, while the stall cell decays at the leading edge. Figure 12 illustrates that stall recovery and temporary surge recovery are similar events.

\section{Conclusions}

Observations from unsteady measurements during stall inception, stall-cell development, rotating stall, and surge were presented. The first signs of stall inception spikes were found within rotor passages. As the stall cell grows after stall inception, the leading edge of the cell will rotate at a higher rate than the trailing edge in the rotor frame suggesting that the stall cell initially increases in size at the leading edge.

Blade loading at the tip and rotor exit total pressure ratio decrease dramatically within the stall cell. Blade lift can decrease to negative values within the stall cell suggesting back-flow. Ahead of the leading edge of the stall cell, the blade lift and rotor exit total pressure ratio surpass prestall values. This is a sign of higher incidence and turning ahead of the stall cell.

The compressor investigated stalls with a single full span stall cell. A single stall cell is also present during surge. There is a striking resemblance between the development of the stall cell for rotating stall and surge cases. The initiation location, initial speed, and initial growth rate of the stall cell are nearly indistinguishable between stall and surge cases. The unsteady event becomes a surge event when the critical recovery value of $C_{x} / U$ is surpassed.

Temporary stall recovery at the end of a surge cycle and recovery from rotating stall are similar events. The trailing

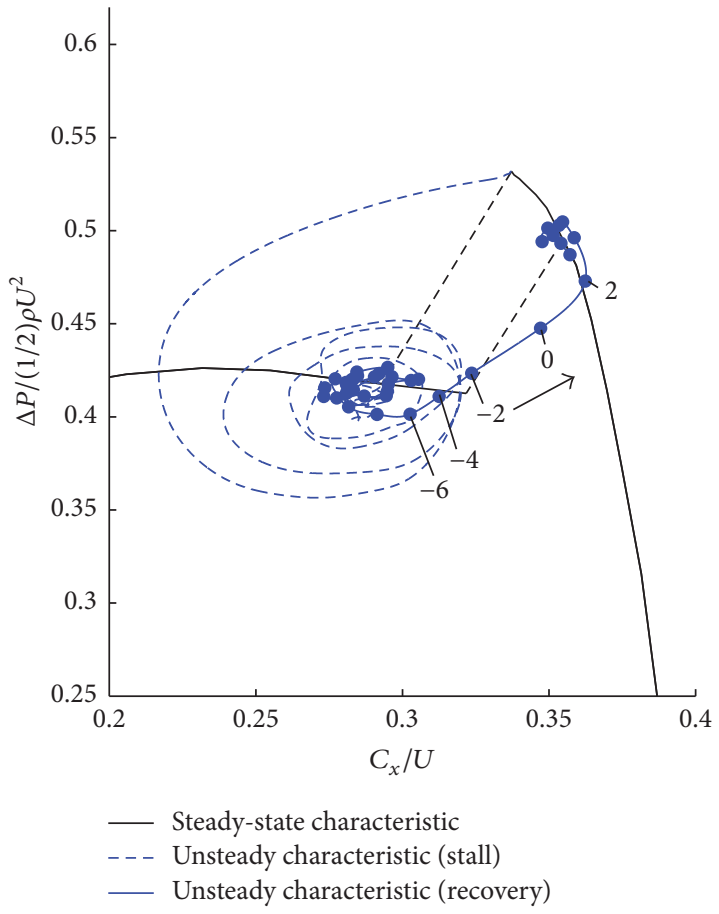

FIGURE 13: Unsteady compressor characteristic during stall and stall recovery.

edge of the stall cell will rotate at the approximate speed as the fully developed stall cell, while the leading edge decreases in rotational speed in the rotor frame. During recovery from compressor stall, the stall cell decays at the leading edge.

Compressor surge was long thought to be an axisymmetric phenomenon. This research has shown that while global fluctuations in mass flow and pressure are present during surge events, local asymmetric instabilities similar to those seen during rotating stall may also take place. Fully 
understanding these instabilities may lead to new methods for delaying or mitigating their effects.

\section{Conflicts of Interest}

The authors declare that they have no conflicts of interest.

\section{References}

[1] T. R. Camp and I. J. Day, "A study of spike and modal stall phenomena in a low-speed axial compressor," Journal of Turbomachinery, vol. 120, no. 3, pp. 393-401, 1998.

[2] H. D. Vo, "Rotating stall suppression in axial compressors with casing plasma actuation," Journal of Propulsion and Power, vol. 26, no. 4, pp. 808-818, 2010.

[3] J. D. Cameron, M. A. Bennington, M. H. Ross et al., "The influence of tip clearance momentum flux on stall inception in a high-speed axial compressor," Journal of Turbomachinery, vol. 135, no. 3, Article ID 051005, 2013.

[4] C. S. Tan, I. Day, S. Morris, and A. Wadia, "Spike-type compressor stall inception, detection, and control," Annual Review of Fluid Mechanics, vol. 42, pp. 275-300, 2010.

[5] S. Weichert and I. Day, "Detailed measurements of spike formation in an axial compressor," Journal of Turbomachinery, vol. 136, no. 5, Article ID 051006, 2013.

[6] K. Yamada, H. Kikuta, M. Furukawa, S. Gunjishima, and Y. Hara, "Effects of tip clearance on the stall inception process in an axial compressor rotor," in Proceedings of the ASME Turbo Expo 2013: Turbine Technical Conference and Exposition (GT '13), June 2013.

[7] J. D. Cameron, S. C. Morris, S. T. Barrows, and J.-P. Chen, "On the interpretation of casing measurements in axial compressors," in Proceedings of the 2008 ASME Turbo Expo, pp. 653665, American Society of Mechanical Engineers, New York, NY, USA, June 2008.

[8] I. J. Day, "Stall, surge, and 75 years of research," Journal of Turbomachinery, vol. 138, no. 1, Article ID 2478223, 2015.

[9] E. M. Greitzer, "Surge and rotating stall in axial flow compressors-part i: theoretical compression system model," Journal of Engineering for Gas Turbines and Power, vol. 98, no. 2, pp. 190-198, 1976.

[10] E. M. Greitzer, "Surge and rotating stall in axial flow compressors-part ii: experimental results and comparison with theory," Journal of Engineering for Gas Turbines and Power, vol. 98, no. 2, pp. 199-211, 1976.

[11] A. R. Hickman and S. C. Morris, "Stall and Surge Characteristics of a Two-Volume Compression System," in Proceedings of the 52nd AIAA/SAE/ASEE Joint Propulsion Conference, Salt Lake City, UT, USA, 2016.

[12] I. J. Day, "Axial compressor performance during surge," Journal of Propulsion and Power, vol. 10, no. 3, pp. 329-336, 1994.

[13] H. Schoenenborn and M. de Vries, "Aeroelasticity at reversed flow conditions-part III: reduction of surge loads by means of intentional mistuning," Journal of Turbomachinery, vol. 135, no. 3, Article ID 041009, 2013.

[14] T. Abe, H. Mitsui, and Y. Ohta, "Coexisting phenomena of surge and rotating stall in an axial flow compressor," Journal of Thermal Science, vol. 22, no. 6, pp. 547-554, 2013.

[15] A. R. Hickman, The Transition From Rotating Stall to Surge in an Axial Compressor [Ph.D. thesis], University of Notre DameTurbomachinery Laboratory, 2017.
[16] H. H. Bruun, Hot-wire Anemometry: Principles and Signal Analysis, Oxford University Press, 1995.

[17] J. Lepicovsky and E. P. Braunscheidel, "Measurement of flow pattern within a rotating stall cell in an axial compressor," NASA/TM-2006-214270, NASA, 2006.

[18] G. Pullan, A. M. Young, I. J. Day, E. M. Greitzer, and Z. S. Spakovszky, "Origins and structure of spike-type rotating stall," in Proceedings of the ASME Turbo Expo 2012: Turbine Technical Conference and Exposition (GT '12), pp. 2567-2579, June 2012.

[19] A. R. Hickman and S. C. Morris, "Characteristics of stable rotating stall cells in an axial compressor," in Proceedings of ASME Turbo Expo 2017: Turbomachinery Technical Conference and Exposition, pp. GT2017-GT64901, 2017. 


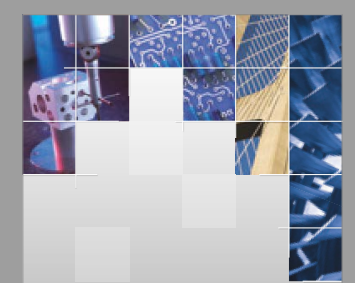

\section{Enfincering}
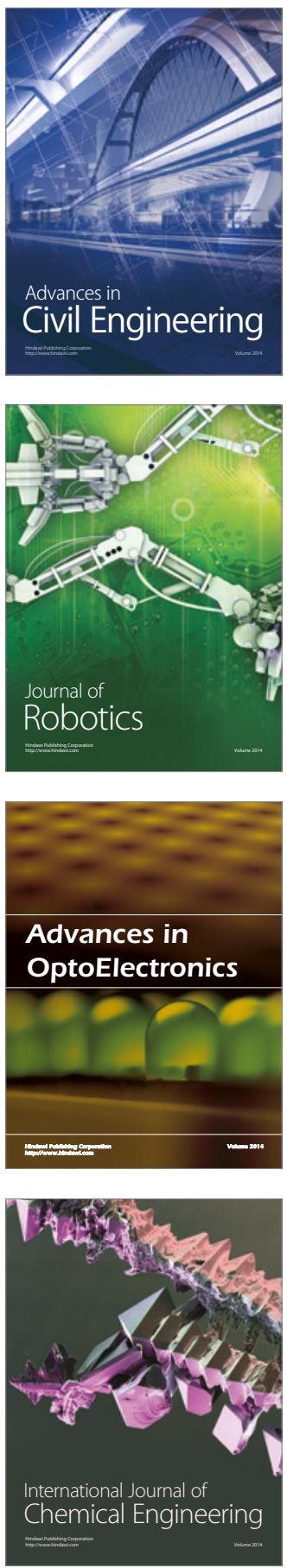

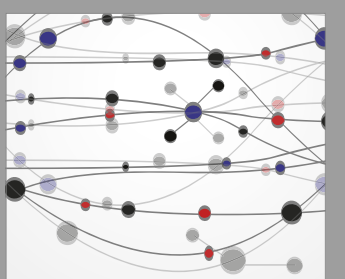

The Scientific World Journal

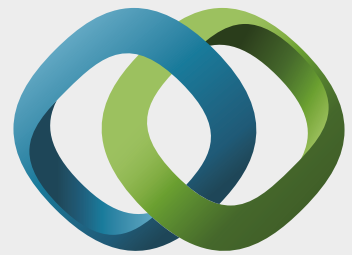

\section{Hindawi}

Submit your manuscripts at

https://www.hindawi.com
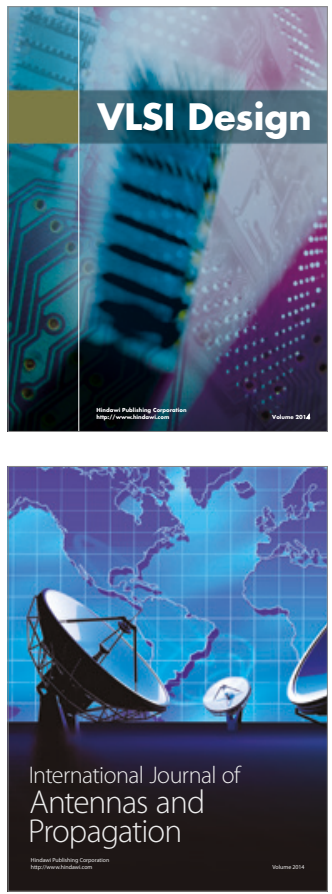

\section{Rotating}

Machinery
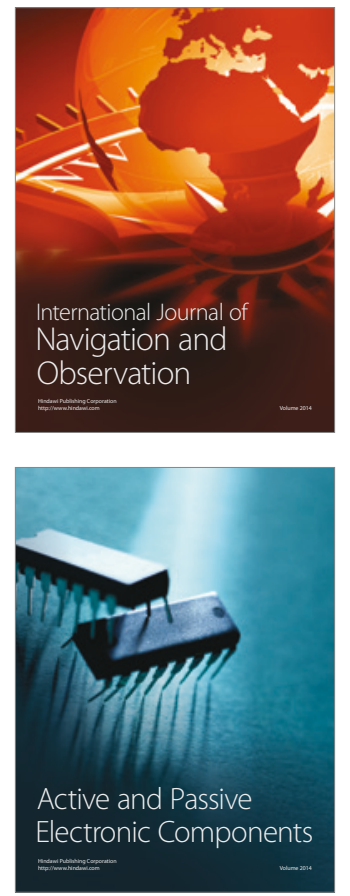
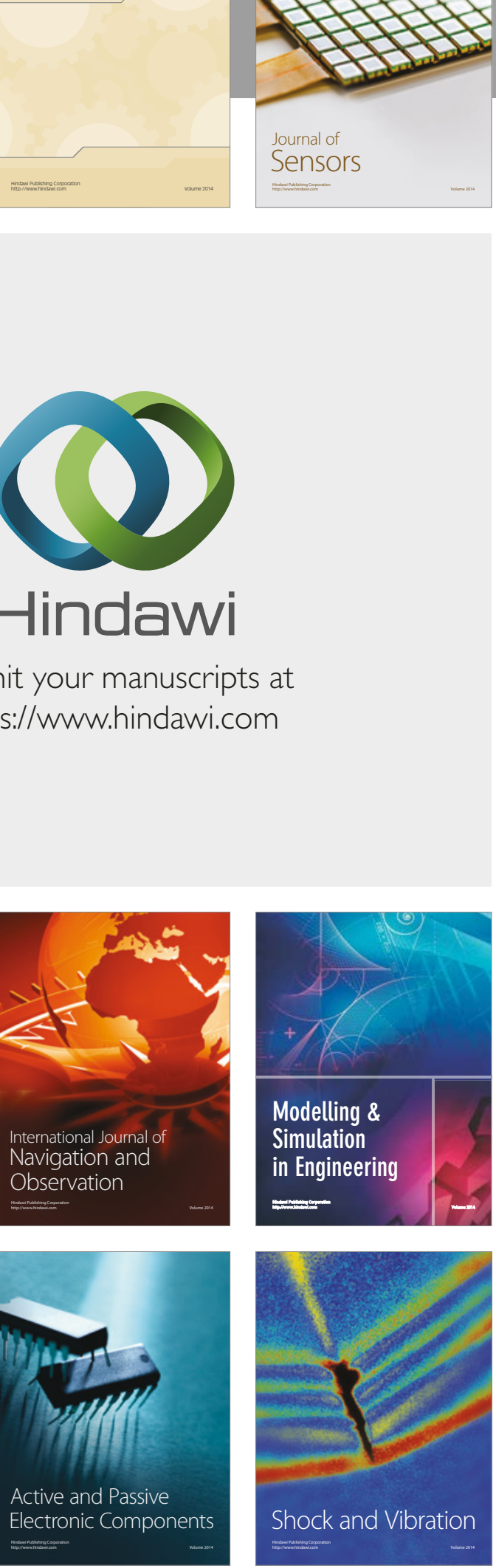
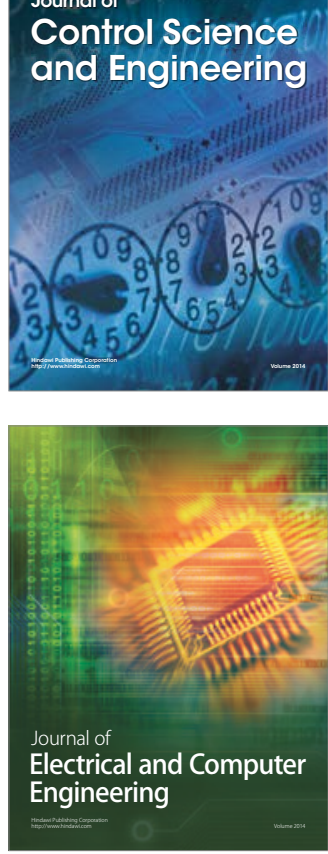

Distributed

Journal of

Control Science

and Engineering
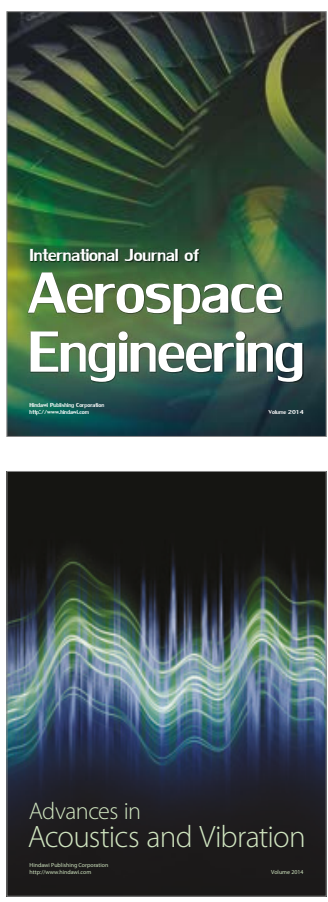

Sensor Networks 